\title{
O gênero Philipotabanus Fairchild (Insecta: Diptera: Tabanidae) na Amazônia, com chave para as fêmeas das espécies e descrição de P. obidensis sp. nov. ${ }^{1}$
}

\author{
Augusto L. HENRIQUES²
}

\section{RESUMO}

É apresentada uma chave dicotômica para os três subgêneros e onze espécies do gênero Philipotabanus Fairchild com registros na Amazônia. É descrita pela primeira vez Philipotabanus (P.) obidensis sp. nov., do estado do Pará. Diagnoses, figuras e distribuição das espécies são fornecidas.

\section{PALAVRAS-CHAVE}

Diptera, Tabanidae, gênero Philipotabanus, Amazônia, Taxonomia.

\section{The genus Philipotabanus Fairchild (Insecta: Diptera: Tabanidae) in the Amazon Region, with a key to the female species and description of P. obidensis sp. nov.}

\section{ABSTRACT}

A key to eleven species and the three subgenera of Amazonian Philipotabanus Fairchild is presented. Philipotabanus (P.) obidensis sp. nov., from Pará State, is described for the first time. Diagnosis, figures and distribution are presented for all species.

\section{KEY WORDS}

Diptera, Tabanidae, Philipotabanus, Amazonia, Taxonomy.

${ }^{1}$ Parte da Tese de doutorado apresentado no PPG-BTRN - INPA/UFAm, Manaus, AM.

${ }^{2}$ Coordenação de Pesquisas em Entomologia - Instituto Nacional de Pesquisas da Amazônia, Cx. postal 478, CEP69.011-970, Manaus, AM, Brasil. loureiro@inpa.gov.br 


\section{INTRODUÇÃO}

O gênero Philipotabanus, descrito em Fairchild (1943) como subgênero de Tabanus e elevado à categoria de gênero em Fairchild (1964), engloba espécies com os seguintes caracteres: tamanho pequeno a médio $(7-15 \mathrm{~mm})$, basicosta com setas esparsas, ocasionalmente glabra. Fronte estreita a muito estreita, calo frontal clavado ou espiniforme, mais estreito que a fronte. Probóscide curta ou longa, labelo membranoso e pruinoso. Palpo moderadamente inflado a muito delgado. Tubérculo ocelar presente, mesmo que às vezes inconspícuo, geralmente com fracos vestígios dos ocelos. Antena com escapo tão largo quanto longo, ou mais largo, pedicelo com pequena projeção dorsal, flagelo largo a delgado com marcada angulação dorsal na placa basal, sem formar espinho ou dente. Asa quase sempre com padrão contrastante de colorido. Também existem formas com apenas fraca mancha abaixo do pterostigma. Pernas delgadas. Olhos glabros, unicoloridos, verdes, avermelhados ou bronze em vida.

Este gênero neotropical ocorre desde a bacia amazônica e leste da Bolívia, se estendendo através das Guianas, Venezuela, Colômbia e América Central até o México. Vinte e oito espécies estão catalogadas (Fairchild \& Burger, 1994). Os três subgêneros reconhecidos estão representados na região amazônica.

Pouco se conhece sobre a biologia das espécies de Philipotabanus. Existem registros de algumas espécies que voam no dossel da floresta e algumas que freqüentemente são registradas no crepúsculo. Não são conhecidos os hospedeiros naturais, até agora foram registrados ataques apenas no homem e cavalo.

\section{MATERIAL E MÉTODOS}

A área de estudo compreende a Amazônia biogeográfica, definida pelos domínios morfoclimáticos e fitogeográficos (Ab'Saber, 1977).

Dados sobre período de atividade de vôo e distribuição geográfica das espécies estudadas foram reportados dos seguintes trabalhos: Wilkerson (1979), Fairchild (1986), Wilkerson \& Fairchild (1985), Henriques \& Gorayeb (1993), Fairchild \& Burger (1994), Henriques (1995), Henriques \& Rafael (1999). Descrições originais das espécies, anotaçōes nas etiquetas dos espécimes e observações pessoais também constituíram fontes de informação para estes tópicos.

A terminologia morfológica segue McAlpine (1981), com a seguinte adaptação: o flagelo antenal, constituído por cinco flagelômeros, por convenção foi dividido em primeiro flagelômero (placa basal) e estilo, este último constituído por quatro anéis.

Os locais de depósito do material estudado são o Instituto Nacional de Pesquisas da Amazônia, Manaus, Amazonas, Brasil (INPA) e o Museu Paraense Emílio Goeldi, Belém, Pará, Brasil (MPEG).

\section{RESULTADOS E DISCUSSÃO}

\section{Gênero Philipotabanus Fairchild}

Tabanus, subg. Philipotabanus Fairchild, 1943: 453. Espécietipo Tabanus ebrius Osten Sacken (des. orig.).

\section{CHAVE DE SUBGÊNEROS E ESPÉCIES PARA AS FÊMEAS DE Philipotabanus COM REGISTROS PARA A AMAZÔNIA}

1 Asa com padrão de mancha escura irregular, de extensão variável, sempre com áreas hialinas ao redor das veias transversais e forquilha da veia r4+5 (Figs. 2a, d,f). Fronte estreita (Fig. 1a, b,d-f), índice frontal 7,0 ou mais. Se asa apenas fumosa com fraca mancha abaixo do pterostigma, fronte estreita, índice frontal 7,0 ou mais ...(Philipotabanus) .2

1' Asa com mancha escura abaixo do pterostigma, de extensão variável, mas sem áreas hialinas ao redor das veias transversais no ápice da célula discal e forquilha da veia $\mathrm{R} 4+5$, quando inclusas em mancha escura. Fronte variável. Se asa apenas fumosa com fraca mancha escura abaixo do pterostigma, fronte menos estreita, índice frontal não acima de seis ................................................ 6

2 Asa apenas enfuscada (Figs. 2b, e). Estigma escuro com fraca mancha abaixo ...............................................................

2' Asa com extensa mancha escura irregular ..........................4

3 Dorso do abdômen de cor azulada (púrpura) intensa quando observado em vista posterior. Escuto e escutelo marrons com pêlos escuros stigmaticalis

3' Dorso do abdômen com leve tom azulado, nítidas bandas claras transversais. Escuto e escutelo marrom-claros com pêlos amarelos predominantes. obidensis sp.n.

4 Tamanho 10,5-12mm. Índice frontal maior que sete. Ápice da asa hialino, mancha escura da asa alcançando o ápice das células $r 5$ e mediais (Fig. 2f) tenuifasciatus 4' Tamanho menor. Ápice da asa enfuscado .......................... 5

5 Tamanho $7-9 \mathrm{~mm}$. Índice frontal maior que sete. Calo frontal (Fig. 1a) marrom-escuro ............................... magnificus 5) Tamanho $9-10 \mathrm{~mm}$. Índice frontal menor que sete. Calo frontal (Fig. 1d) marrom .......................................... reticulatus 6(1')Espécies delgadas. Fronte estreita, índice frontal 7,0 ou mais. Palpo e antena delgados. Olhos verdes brilhantes em vida ...(Melasmatabanus) ....... 7

6. Espécies mais robustas. Fronte menos estreita, índice frontal não acima de 6,0. Palpo inflado. Antena mais larga. Olhos verdes ou avermelhados em vida (Mimotabanus) ...... 9

7 Asa quase completamente escura, apenas pequenas manchas hialinas distalmente nas células basilares, ápice da asa e lobo anal mais claros..... nigripennis

7' Pintura da asa menos extensa, localizada na metade proximal das células basilares e mancha larga abaixo do pterostigma ..... 8

8 Faixa escura abaixo do pterostigma estreita, face distal 
irregular, praticamente não ultrapassando o ápice da célula discal criton

8' Faixa escura abaixo do pterostigma mais extensa, alcançando metade proximal das células $\mathrm{m} 1$ e $\mathrm{m} 2$ e mais da metade da $\mathrm{r} 5$ (Fig. 2c) pictus

9(6') Tamanho 10mm. Índice frontal 4,3-5,1 opimus

9' Tamanho maior, em torno de $13 \mathrm{~mm}$. Índice frontal variável 10

10 Índice frontal 6,0. Antena marrom-escura fucosus 10' Índice frontal 4,5. Antena laranja phalaropygus

\section{Subgênero Philipotabanus Fairchild, 1943}

Caracterizado por apresentar asa com padrão de pintura escura irregular com fenestras hialinas ao redor das veias transversais e forquilha da veia $\mathrm{r} 4+5$. Também pode apresentar asa apenas fumosa com pterostigma escuro, contrastante. Fronte geralmente estreita a muito estreita, índice frontal acima de 7,0. Palpo muito delgado. Olhos bronze em vida.
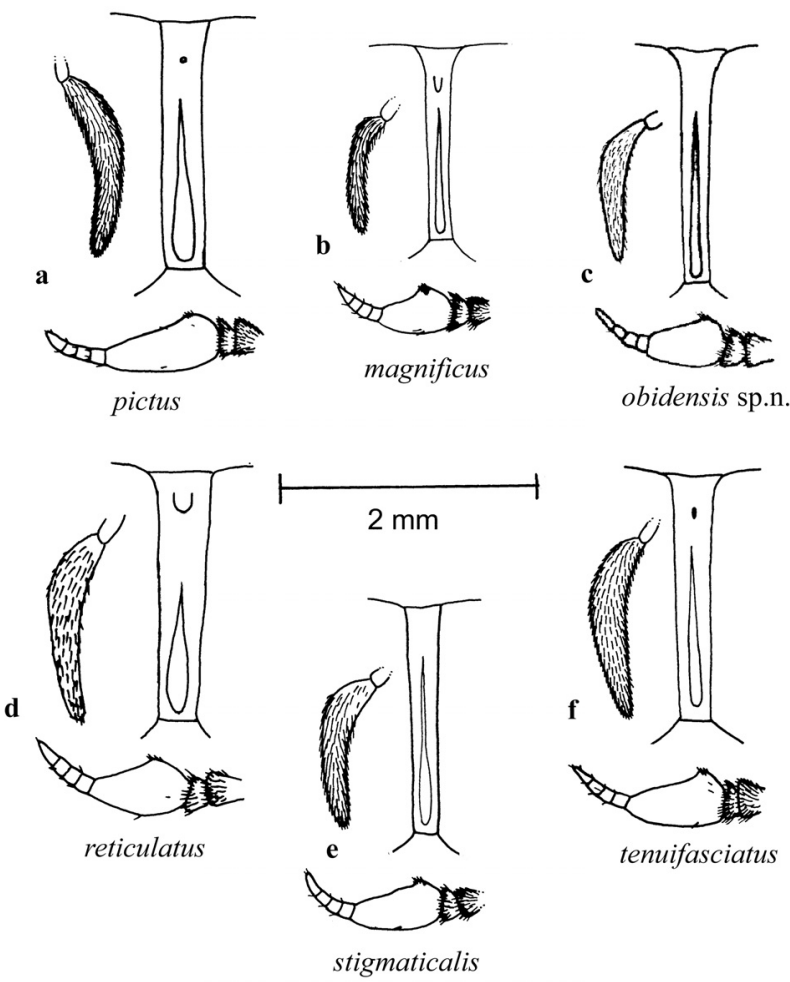

Figura 1 - Palpos, frontes e antenas de seis espécies de Philipotabanus (Diptera: Tabanidae) da Amazônia. a) P. magnificus b) P. obidensis sp. n. Holótipo fêmea c) $P$. pictus d) $P$. reticulatus e) $P$. stigmaticalis f) $P$. tenuifasciatus.

\section{Philipotabanus magnificus (Kröber)}

(Figs. 1a, 2a)

Tabanus magnificus Kröber, 1934: 299 (pre ocup. formosus Kröber, 1930).

Retirado de Wilkerson (1979) - Fêmea: Tamanho 7 - 9mm. Índice frontal 7 - 11. Espécie marrom-amarelada a marromescura dorsalmente. Calo marrom-escuro, espiniforme. Escapo e pedicelo amarelados com pêlos marrons, primeiro flagelômero amarelo-laranja com angulação obtusa dorsalmente, estilo geralmente contrastante, marrom-escuro. Pleura e coxas amareloacinzentadas, restante das pernas marrom-escuro com pêlos escuros. Asa com margem enfuscada e mancha escura irregular
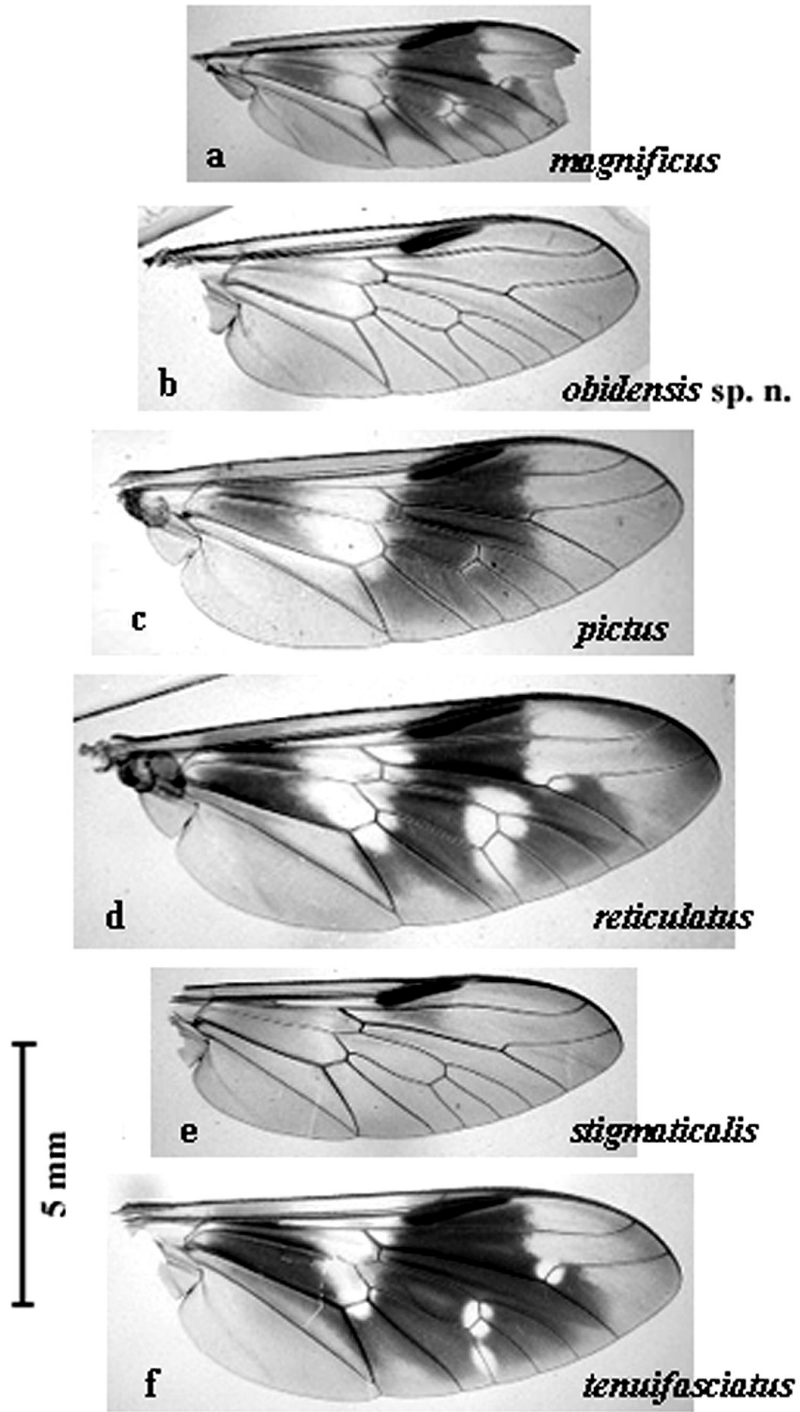

Figura 2 - Asas de seis espécies de Philipotabanus (Diptera: Tabanidae) da Amazônia. a) $P$. magnificus b) $P$. obidensis sp. n. - Holótipo fêmea c) $P$. pictus d) $P$. reticulatus e) $P$. stigmaticalis f) $P$. tenuifasciatus. 
abrangendo base das células basilares, faixa abaixo do pterostigma atravessando o meio da célula discal até a veia cup e adentrando na base da célula $\mathrm{r} 4,2 / 3$ da célula $\mathrm{r} 5$ e meio das $\mathrm{m} 1$ e $\mathrm{m} 2$. Basicosta com algumas cerdas curtas. Tergitos com pêlos pretos e pruinosidade azulada, exceto alguns pêlos esbranquiçados na lateral dos tergitos 1-3 e em alguns espécimes pequena mancha mediana de pêlos claros nos tergitos 2 e 3. Esternitos 2-4 com borda posterior mais clara com pêlos esbranquiçados, restante com pêlos amarronzados.

Philipotabanus magnificus tem sido coletado mais freqüentemente no crepúsculo no estrato inferior da floresta primária, entretanto também é encontrada no dossel. Existem registros de ataque em preguiça e no homem (Fairchild, 1986).

Material examinado: PANAMÁ, Chiriqui, iv-v.1977, Wolda col., det. Fairchild, 1988 (fêmea MPEG); Darien, 5.v.1967, sem coletor, det. Fairchild, 1988 (fêmea INPA); COLÔMBIA, Valle, Lower Anchicaya, 400m, vi.1975, Wilkerson col. (fêmea MPEG); idem, iii.1976 (fêmea MPEG); Chocó, Curiche River, v.1967, sem coletor, det. Fairchild, 1988 (fêmea MPEG); Raposo, i.1963, sem coletor, det. Fairchild, 1988 (fêmea MPEG); EQUADOR, Rio Palenque, 035'S-79²2’W, ii.1976, Wood col. (2 fêmeas INPA).

Distribuição: Honduras até Equador; Venezuela.

Ocorrência: janeiro a dezembro, com maior freqüência no período chuvoso.

\section{Philipotabanus obidensis sp.nov.}

(Figs.1b, 2b)

Espécie de aspecto marrom; dorso do abdômen mais escuro que o tórax e com nítidas bandas esbranquiçadas; fronte estreita, asa praticamente hialina com fraca mancha abaixo do pterostigma, este marcadamente escuro.

Fêmea: Tamanho 8,8 mm. Asa 9,1 $\mathrm{mm}$. Olhos glabros. Fronte com pruína marrom-acinzentada, Índice frontal 7,8, calo frontal marrom-escuro espiniforme, vértice liso brilhante, ocelos inconspícuos. Subcalo, face e gena com pruína marrom ou acinzentada; pêlos da última marrons ou esbranquiçados em certa incidência de luz. Antena marrom-amarelada, placa basal mais clara, amarelada. Palpo marrom com pêlos pretos. Labelo membranoso. Tórax com escuto e escutelo marrons com pêlos amarelos e pretos misturados. Notopleura marrom com pêlos amarelos na regiāo superior e pretos na região inferior. Anepisterno com pêlos amarelos na borda superior, o restante com pêlos pretos; anepisterno e catepisterno marrons com pruína acinzentada e pêlos pretos; catatergito mais claro com pêlos amarelados. Pernas marrom-escuras com pêlos pretos. Asa com veias marrons, praticamente toda hialina, exceto por fraca mancha amarronzada que se estende abaixo do pterostigma até próximo à base da célula R1 (1 $1^{\mathrm{a}}$ submarginal); pterostigma marrom. Basicosta glabra. Balancim marrom. Abdômen marrom-escuro com pêlos pretos, exceto por faixa terminal de pruína esbranquiçada e pêlos claros em todos os segmentos. Dorso do abdômen com reflexos azulados (púrpura) quando em vista posterior.

Holótipo fêmea: BRASIL, Pará, Óbidos, Ramal do Benedito, próximo Lago Cururu, $01^{\circ} 49^{\prime} 22^{\prime \prime} \mathrm{S}, 55^{\circ} 07^{\prime} 01^{\prime \prime W}, 29-$ 31.viii.2001, suspensa alta, J.A. Rafael \& J.F. Vidal (INPA); 4 Parátipos fêmea: mesmos dados do Holótipo (INPA).

Discussão: Esta espécie é semelhante a P. stigmaticalis, largamente distribuída na Amazônia, e também foi coletada no dossel da floresta como é freqüente com stigmaticalis. Difere desta principalmente por ser mais clara, escuto e escutelo marromclaros com pêlos amarelos predominantes, mancha na asa abaixo do pterostigma mais fraca, intensidade menor da cor azulada (púrpura) no dorso do abdômen e nítidas bandas dorsais esbranquiçadas no abdômen.

\section{Philipotabanus reticulatus (Kröber)}

(Figs. 1d, 2d)

Tabanus reticulatus Kröber, 1930: 298, fig.20.

Caracteres redescritos. Fêmea: Tamanho $9-10 \mathrm{~mm}$. Índice frontal 6. Corpo marrom. Fronte quase paralela. Calo frontal marrom brilhante. Antena amarela, escurecendo em direção ao ápice. Palpo marrom-claro com pêlos pretos. Pêlos da gena esbranquiçados. Escuto e escutelo marrons com pêlos escuros e claros. Pleura mais clara com pêlos claros. Pernas marrom-escuras, tíbia média mais clara. Asa com margem enfuscada e áreas escuras localizadas na porção proximal das células basilares e região posterior, a partir do estigma, exceto veias transversais, porção subapical das células r1 e r2+3 e porção anterior da r4, hialinas. Margem posterior dos tergitos com estreita faixa de pêlos claros, mais larga no meio.

Material examinado: BOLÍVIA, La Paz, S. Inicua, Rio Alto Beni, 1.100m, i.1976, Peña col. (fêmea INPA, fêmea MPEG).

Distribuição: leste do Peru e da Bolívia.

Ocorrência: janeiro, fevereiro, novembro, dezembro.

\section{Philipotabanus stigmaticalis (Kröber)}

(Figs. 1e, 2e)

Tabanus stigmaticalis Kröber, 1931: 299.

Caracteres redescritos. Espécie facilmente distinguível das demais do subgênero por apresentar o seguinte conjunto de caracteres: Fêmea: Tamanho 7,5-10mm. Índice frontal 7,2 9,0. Tórax marrom a marrom-escuro com pêlos predominantemente escuros. Pernas marrons a marrom-escuras. Asa fumosa, estigma marrom com pequena mancha abaixo. Abdômen marrom-escuro a preto com pêlos escuros e pruína azulada. Esta espécie, como discutida em Fairchild (1964), apesar de não possuir o padrão subgenérico da pintura alar, é posicionada aqui pelos caracteres da cabeça. 
Philipotabanus stigmaticalis é mais freqüentemente coletada no estrato superior da floresta primária.

Material examinado: 120 fêmeas e 1 macho do MPEG: BRASIL, Amapá, Serra do Navio, v; Pará, Benevides, vi,xii; Serra Norte, ii,x; Amazonas, Manaus, iv, det. Gorayeb, 1982; Maraã, $\mathrm{x}$,xi; Acre, Porto Acre, x,xi; Rondônia, Ouro Preto do Oeste, iii,iv.xi, det. Gorayeb, 1990; 206 fêmeas e 4 machos do INPA: BRASIL, Roraima, Pacaraima, iii; Pará, Santarém, Vila Inanu, xii; Amazonas, Manaus e imediaçōes, i-v,vii-xii, Morro dos Seis lagos, ix,x; Parque Nacional do Jaú, vii,xi; Rondônia, Ariquemes, $\mathrm{x}$.

Distribuiçāo: Guiana; Brasil (Acre; Amapá; Amazonas; Pará; Rondônia; Roraima).

Ocorrência: janeiro a dezembro, com maior freqüência no período de estiagem.

\section{Philipotabanus tenuifasciatus (Kröber)}

(Figs. 1f, 2f)

\section{Tabanus tenuifasciatus Kröber, 1930: 296, figs. 17, 17a.}

Caracteres redescritos. Fêmea: Tamanho 10,5-11,9mm. Índice frontal 6,8-7,4. Calo frontal marrom a marrom-escuro, quase filiforme. Antena amarelo-laranja. Último anulus um pouco escurecido no ápice. Escuto, notopleura e escutelo marromamarelados com pêlos escuros, ápice do escutelo mais claro. Os pêlos do escutelo, em vista anterior, apresentam reflexos claros. Pleura e esterno um pouco mais claros com pêlos escuros e claros. Pernas geralmente marrom-escuras com fêmures anterior e posterior mais escuros e tíbia e tarso médios mais claros. Asa com extensa mancha escura irregular. Além das fenestras características do subgênero, lobo anal, meio da célula costal e $1 / 2$ apical das células r $1, \mathrm{r} 2+3$ e r 4 mais claros. Basicosta com cerdas quase tão densas quanto as adjacências da veia costa. Abdômen marromescuro a preto com pruína azulada e pêlos predominantemente escuros, pêlos claros apenas na lateral dos tergitos 1-3. Medianamente na margem posterior do tergito 4 e esparsamente nos esternitos, estes mais concentrados na margem posterior dos esternitos 2-4.

Philipotabanus tenuifasciatus, espécie da Amazônia ocidental, habita a floresta primária. Ocasionalmente ataca o homem.

Material examinado: BRASIL, Amazonas, Benjamin Constant, Nova Aliança, $04^{\circ} 15^{\prime} 20^{\prime \prime} S-69^{\circ} 20^{\prime} 42^{\prime \prime}$, iv.2004, em luz mista, F.F. Xavier col. (fêmea INPA), Rio Urucu, RUC-30, x,xi.1994, Silva col. (10 fêmeas INPA); Acre, Parque Nacional da Serra do Divisor, 7²8'S-7341'W, xi.1996, Morato col. (fêmea INPA); Porto Acre, x,xi.1991, Gorayeb et al. col. (2 fêmeas MPEG).

Distribuição: leste da Colômbia, do Equador e do Peru; Brasil (Acre; Amazonas).

Ocorrência: outubro, novembro.

\section{Subgênero Melasmatabanus Fairchild, 1964}

Este grupo é semelhante estruturalmente ao subgênero nominal, porém a pintura da asa não apresenta fenestras ao redor das veias transversais.

\section{Philipotabanus criton (Kröber)}

Tabanus criton Kröber, 1934: 304. Exemplares não examinados.

Retirado de Wilkerson (1979) - Fêmea: Tamanho 8-11mm. Índice frontal 6,1-9,0. Fronte um pouco divergente em cima. Calo marrom-escuro, delgado, cerca de metade da largura da fronte na base e 2/3 da altura. Escapo antenal marromacinzentado, restante da antena amarelo-laranja. Primeiro flagelômero duas vezes o comprimento que a largura, com angulação obtusa dorsal. Pêlos da gena marrons, esparsos. Probóscide membranosa. Escuto marrom a marrom-escuro com pêlos escuros e claros misturados. Escutelo, concolor com o escuto, com pêlos pretos na região anterior e pêlos claros apicalmente. Pleura e coxas marrom-escuras com pruína acinzentada e pêlos escuros. Restante das pernas marrom-escuro com pêlos escuros. Asa escura na $1 / 2$ proximal das células basilares e larga faixa abaixo do estigma até base da célula cuA1. Lobo anal apenas difusamente escurecido. Basicosta com cerdas tão densamente como as adjacências da veia costa. Abdômen marrom-escuro com pruína azulada, predominantemente com pêlos pretos, pêlos brancos lateralmente nos tergitos $2 \mathrm{e} 3$, medianamente no tergito 4 e margem lateral dos esternitos 2 e 3 .

Philipotabanus criton tem sido coletada ocasionalmente na luz e atacando o cavalo e o homem (Fairchild, 1986).

Distribuição: Panamá, Colômbia, leste do Equador, Brasil (Mato Grosso).

Ocorrência: julho a dezembro.

\section{Philipotabanus nigripennis Wilkerson}

Philipotabanus nigripennis Wilkerson, 1979: 321, fig. 105. Exemplares não examinados.

Retirado da descrição e figuras originais - Fêmea: Tamanho $11-14 \mathrm{~mm}$. Índice frontal 5,1-6,3. Espécie com tórax amarelado e pernas pretas. Asa extensivamente enegrecida, no máximo pequenas manchas hialinas no ápice das células basilares, raramente em outras células, lobo anal e ápice das células $r 1$, $\mathrm{r} 2+3$ e r 4 difusamente escurecidas a hialinas. Basicosta com cerca de 10 cerdas curtas. Abdômen enegrecido com triângulo de pêlos brancos no tergito $4 \mathrm{e}$ algumas vezes um triângulo menos distinto no tergito 3 .

Distribuição: Colômbia; leste do Equador.

Ocorrência: janeiro a maio, agosto, dezembro.

\section{Philipotabanus pictus Gorayeb \& Rafael}

(Figs. 1c, 2c)

Philipotabanus pictus Gorayeb \& Rafael, 1984: 46, figs. 1, 3 a. 
Caracteres redescritos. Fêmea: Tamanho 10,8mm. Índice frontal 7,5. Calo frontal marrom a preto brilhante. Dois primeiros segmentos da antena marrom-amarelados com pêlos pretos, primeiro flagelômero amarelo-laranja, estilo um pouco mais escuro, último anulus com ápice enegrecido. Probóscide com labelo membranoso. Escuto marrom com pêlos escuros e claros misturados. Escutelo marrom-amarelado com pêlos brancos. Pleura marrom a preto-acinzentada com pêlos brancos. Pernas, exceto coxas mais claras, marrons a pretas com pêlos pretos. Asa com pintura marrom na metade proximal das células basilares $\mathrm{e}$ larga faixa transversal abaixo do estigma até, difusamente, célula cuA1. Basicosta com cerdas curtas esparsas ou glabras. Tergitos marrom-escuros com pêlos pretos e pruinosidade azulada, exceto lateral dos tergitos 1-3 e triângulo mediano no tergito 4 com pêlos brancos. Esternitos mais claros com margem posterior com pêlos brancos.

Material examinado: BRASIL, Rondônia, Vilhena, xi.1979, Arias col. (Holótipo fêmea INPA, Parátipo fêmea MPEG); Ouro Preto do Oeste, xi.1984, Ramos col., det. Gorayeb, 1986 (2 fêmeas MPEG); Pará, Tucuruí, Morro do senador, 0359'23"S$49^{\circ} 44^{\prime} 45^{\prime \prime} \mathrm{W}$, xii.2001, Arm. suspensa alta, Rafael \& Vidal cols.

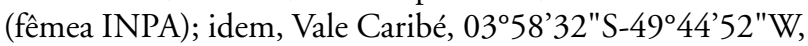
xii.2001, Arm. Malaise, Rafael \& Vidal cols. (fêmea INPA)

Distribuição: Brasil (Pará, Mato Grosso; Rondônia).

Ocorrência: novembro.

\section{Subgênero Mimotabanus Fairchild, 1964}

Semelhante ao grupo anterior em apresentar mancha escura da asa sem as fenestras, porém pode estar reduzida a pequena mancha abaixo do pterostigma, fronte mais larga, calo clavado e palpo menos delgado.

\section{Philipotabanus fucosus Fairchild}

Philipotabanus fucosus Fairchild, 1958: 526, figs. 1, 21. Exemplares não examinados.

Retirado da descrição e figuras de Fairchild (1975) - Fêmea: Tamanho 13,5mm. Índice frontal 6,0 -6,3. Fronte um pouco divergente em cima. Calo frontal preto rugoso, mais estreito que a fronte, espiniforme, quase alcançando o tubérculo ocelar. Subcalo com pruína cinza-amarelada. Antena marrom-escura, escapo e pedicelo com pêlos pretos, primeiro flagelômero com forte angulação dorsal, estilo antenal um pouco menor que o primeiro flagelômero. Probóscide com labelo membranoso. Tegumento do escuto e escutelo marrom-avermelhado, suturas mais claras. Pleura e esterno com pruína cinza-escura e pêlos cinza-claros. Pernas marrom-escuras, quase pretas, com pêlos pretos. Asa escura, exceto células basilares e ápice hialinos, margem posterior com pintura difusa. Basicosta com cerdas esparsas. Abdômen com tegumento marrom-escuro, tergito 1, lateral do tergito 2 e meio do tergito 4 com pruína cinza. Lateral dos tergitos 1 e 2 e mancha mediana trapezóide no tergito 4 com pêlos brancos, o restante com pêlos pretos. Esternitos mais claros com pruína cinza e pêlos escuros, exceto margem posterior dos segmentos 2 e 4 com pêlos brancos.

Distribuição: Colômbia (Meta); leste do Peru.

Ocorrência: janeiro, agosto.

\section{Philipotabanus opimus Fairchild}

Philipotabanus opimus Fairchild, 1975: 691, pr. I, figs. 4, 5, pr. II, figs. 2-4.

Caracteres redescritos. Fêmea: Tamanho $10 \mathrm{~mm}$. Índice frontal 4,3-5,1. Tórax e abdômen marrons, escuto com nítidas faixas longitudinais claras. Como Fairchild descreve, a espécie apresenta variação cromática considerável, inclusive na mancha da asa. Calo frontal amarelo, marrom ou quase preto. Mancha no meio da asa quase preta a quase imperceptível. Abdômen, em cima, com triângulos medianos e/ou bandas completas. Espécimes da Colômbia são mais claros tanto no corpo como na asa e são mais uniformes. Espécimes do Peru são mais variáveis, alguns aproximadamente tão claros como o Holótipo, outros mais escuros, sem traços de faixas no escuto e mancha na asa mais escura e mais extensiva. Uma simples fêmea do Equador, danificada, com forte mancha escura na asa. De um modo geral a espécie apresenta coloração marrom, triângulos medianos prateados nos tergitos 2-4 e pernas marrom-escuras a pretas. Basicosta sem cerdas.

Material examinado: COLÔMBIA, N. Santander, Arboledas, vii.1984, Alexander col., det. Fairchild, 1988 (fêmea MPEG).

Distribuição: leste da Colômbia, do Equador e do Peru.

Ocorrência: janeiro, agosto a outubro, dezembro.

\section{Philipotabanus phalaropygus Fairchild}

Philipotabanus phalaropygus Fairchild, 1964: 177, figs. 11a-c. Exemplares não examinados

Retirado da descrição e figuras originais - Fêmea: Tamanho $13,5 \mathrm{~mm}$. Índice frontal 4,5. Fronte aproximadamente paralela. Calo frontal marrom-escuro a preto, largo na base com extensão filiforme em cima, quase alcançando o vértice. Antena laranja, apenas o ápice do último anulus escurecido. Escuto preto com sutura sublateral avermelhada. Escutelo e pleura enegrecidos com pêlos pretos. Pernas pretas com pêlos pretos, tíbia anterior fracamente avermelhada no $1 / 3$ proximal. Asa hialina com mancha preta abaixo do pterostigma incluindo toda célula discal e base das células mediais. Célula costal, metade proximal das células basilares, célula cup, lobo anal e área axilar amarronzados. Basicosta com cerdas curtas esparsas. Tergitos pretos com pêlos concolores, exceto manchas de pêlos branco-amarelados nos ângulos póstero-laterais dos tergitos 1-3 e grande triângulo mediano de pêlos branco-amarelados na margem posterior do tergito 4. Esternitos mais claros com margem posterior esbranquiçada. Esta espécie tem sido coletada 
predominantemente no estrato superior da floresta. Ocasionalmente ataca o homem

Distribuição: Panamá; Colômbia; leste do Peru.

Ocorrência: fevereiro, março, agosto, setembro.

\section{AGRADECIMENTOS}

Ao Conselho Nacional de Desenvolvimento Científico e Tecnológico-CNPq pela concessão de bolsa durante o doutoramento. Ao Dr. José Albertino Rafael (INPA) pela revisão e sugestôes ao trabalho.

\section{BIBLIOGRAFIA CITADA}

Ab'Saber, A.N. 1977. Os Domínios morfoclimáticos na América do Sul. Primeira Aproximação. Geomorfologia, 52: 1-21.

Fairchild, G.B. 1943 (1942). Notes on Tabanidae (Dipt.) from Panama. X. The genus Tabanus Linn., and Resume of the Tabanidae of Panama. Ann. Ent. Soc. Amer., 35(4): 441-474.

Fairchild, G.B. 1958. Notes on Neotropical Tabanidae. II. Desciption of new species and new records for Panama. Ann. Ent. Soc. Amer., 51(6): 517-530.

Fairchild, G.B. 1964. Notes on Neotropical Tabanidae (Diptera). IV. Further new species and new records for Panama. J. Med. Ent., 1(2): 169-185.

Fairchild, G.B. 1975. Notes on Neotropical Tabanidae (Diptera). XVII. Genus Philipotabanus Fchld., Subgenus Mimotabanus Fchld. Ann. Ent. Soc. Amer., 68(4): 689-694.

Fairchild, G.F. 1986. Tabanidae of Panama. Contrib. Amer. Ent. Inst., 22(3): 1-139.

Fairchild, G.B.; Burger, J. F. 1994. A Catalog of the Tabanidae (Diptera) of the Americas South of the United Sates. Memoirs Amer. Ent. Inst., 55: 1-249.

Gorayeb, I.S.; Rafael, J.A. 1984. Tabanidae (Diptera) da Amazônia. V. Descrição de duas espécies novas. Bol. Mus. Para. Emílio Goeldi, Sér. Zool., 1(1): 45-55.
Henriques, A.L. 1995. A Coleção de Tabanidae (Insecta: Diptera) do Instituto Nacional de Pesquisas da Amazônia (INPA), Manaus, Amazonas, Brasil. Bol. Mus. Para. Emílio Goeldi, sér. Zool., 11(1): 57-99.

Henriques, A.L.; Gorayeb, I.S. 1993. A Coleção de Tabanidae Insecta: (Diptera) do Museu Paraense Emílio Goeldi, Belém, Pará, Brasil. Goeldiana Zoologia, 20: 1-23.

Henriques, A.L.; Rafael, J.A. 1999. Tabanidae (Diptera) from Parque Nacional do Jaú, Amazonas, Brazil, with description of two new species of Diachlorus Osten Saken. In: A collection of articles on Diptera commemorative the life and work of Graham B. Fairchild. Mem. Ent. International, Associated Publishers, Vol. 14: 195-222.

Kröber, O. 1930. Die Tabanidenuntergattung Phaeotabanus Lutz. Zool. Anz., 86: 273-300.

Kröber, O. 1931. Neue süd-und mittelamerikanische Arten der Dipterengattung Tabanus L. Stettin. Ent. Ztg. 92: 275-305.

Kröber, O. 1934. Catalogo dos Tabanidae da América do Sul e Central, incluindo o México e as Antilhas. Rev. Entom., Rio de Janeiro 4(2-3): 222-276, 291-333.

McAlpine, J.F. 1981. Morphology and Terminology, p. 9-63. In: McAlpine, J. F. et al. (eds.). Manual of Nearctic Diptera (Monograph n ${ }^{\circ}$ 27), Res. Branch, Agriculture, Canada.

Wilkerson, R.C. 1979. Horse flies (Diptera: Tabanidae) of the Colombian departments of Chocó, Valle and Cauca. Cespedesia, (Cali, Colômbia), 8(31-32): 99-432.

Wilkerson, R.C.; Fairchild, G.B. 1985. A Checklist and generic Key to the Tabanidae (Diptera) of Peru with Special Reference to the Tambopata Reseved Zone, Madre de Dios. Rev. Per. Ent., 27: 37-53. (1984).

Recebido em 19/10/2004

Aceito em 06/11/2006 
